\title{
Nociceptors Lacking TRPV1 and TRPV2 Have Normal Heat Responses
}

\author{
C. Jeffery Woodbury, ${ }^{1 \star}$ Melissa Zwick, ${ }^{2 \star}$ Shuying Wang, ${ }^{2}$ Jeffrey J. Lawson, ${ }^{1}$ Michael J. Caterina, ${ }^{3}$ Martin Koltzenburg, ${ }^{4}$ \\ Kathryn M. Albers, ${ }^{2}$ H. Richard Koerber, ${ }^{1}$ and Brian M. Davis ${ }^{2}$ \\ Departments of ${ }^{1}$ Neurobiology and ${ }^{2}$ Medicine, University of Pittsburgh, Pittsburgh, Pennsylvania 15261, ${ }^{3}$ Department of Biological Chemistry, Johns \\ Hopkins School of Medicine, Baltimore, Maryland 21205, and ${ }^{4}$ University College London, London WC1N 1EH, United Kingdom
}

Vanilloid receptor 1 (TRPV1) has been proposed to be the principal heat-responsive channel for nociceptive neurons. The skin of both rat and mouse receives major projections from primary sensory afferents that bind the plant lectin isolectin B4 (IB4). The majority of IB4-positive neurons are known to be heat-responsive nociceptors. Previous studies suggested that, unlike rat, mouse IB4-positive cutaneous afferents did not express TRPV1 immunoreactivity. Here, multiple antisera were used to confirm that mouse and rat have different distributions of TRPV1 and that TRPV1 immunoreactivity is absent in heat-sensitive nociceptors. Intracellular recording in TRPV1 ${ }^{-1-}$ mice was then used to confirm that TRPV1 was not required for detecting noxious heat. TRPV $1^{-1-}$ mice had more heatsensitive neurons, and these neurons had normal temperature thresholds and response properties. Moreover, in TRPV1 ${ }^{-l-}$ mice, $82 \%$ of heat-responsive neurons did not express immunoreactivity for TRPV2, another putative noxious heat channel.

Key words: capsaicin; hypersensitivity; nociception; sensory neurons; skin; pain

\section{Introduction}

Sensory neurons are a heterogeneous cell population that responds to a broad range of stimuli. Noxious heat sensations have been proposed to be detected by two vanilloid receptors; TRPV1 (VR1) is thought to respond to temperatures above $43^{\circ} \mathrm{C}$ (Caterina et al., 2000), whereas a related family member, TRPV2 (VRL1), has been proposed to respond to temperatures above $52^{\circ} \mathrm{C}$ (Caterina et al., 1999). TRPV1 is a nonselective cation channel expressed by primary sensory neurons that is activated by capsaicin, low pH $(\mathrm{pH}<6)$, and heat (Caterina et al., 1997; Davis et al., 2000). TRPV1 is found primarily in small-diameter dorsal root ganglion (DRG) neurons and is expressed by both peptidergic and non-peptidergic primary afferents. TRPV2 does not respond to capsaicin and appears to be more widely expressed, being found in all sizes of sensory neurons (Caterina et al., 1999; Ma, 2001). More recently, a third family member has been identified (TRPV3) that has reported temperature thresholds from 23 to $39^{\circ} \mathrm{C}$ and is expressed in the skin as well as the central and

\section{Received April 15, 2004; revised May 25, 2004; accepted May 25, 2004.}

This work was supported by National Institutes of Health Grants NS31826 (B.M.D.), NS33730 (K.M.A.), NS044094 (C.J.W.), and NS23725 (H.R.K.). We thank Dr. David Julius (University of California, San Francisco, San Francisco, CA) for the TRPV1M antibody, John Burkett (University of Kentucky, Lexington, KY) and Weiwen Wang (University of Pittsburgh, Pittsburgh, PA) for excellent technical assistance, and Patrick Crumrine (University of Kentucky) for statistical expertise.

${ }^{*}$ C.J.W. and M.Z. contributed equally to this work.

Correspondence should be addressed to Dr. Brian M. Davis, Department of Medicine, Division of Gastroenterology, Hepatology, and Nutrition, Scaife Hall, Room S-843, 3550 Terrace Street, Pittsburgh, PA 15261. E-mail: bmd1@pitt.edu.

C. J. Woodbury's present address: Department of Zoology and Physiology, University of Wyoming, Laramie, WY 82071.

M. Zwick's present address: Department of Natural Sciences, Longwood University, Farmville, VA 23909. D0I:10.1523/JNEUROSCI.1421-04.2004

Copyright $\odot 2004$ Society for Neuroscience $\quad$ 0270-6474/04/246410-06\$15.00/0 peripheral nervous systems (Peier et al., 2002; Smith et al., 2002; Xu et al., 2002). A fourth heat-sensitive TRP channel, TRPV4, has been isolated, but its response properties suggest it is not involved in nociception, detecting non-noxious warm temperatures (Guler et al., 2002; Watanabe et al., 2002).

The majority of neurons that respond to noxious heat fall into two classes of nociceptive neurons distinguished by their growth factor dependence. NGF-dependent nociceptors express tyrosine kinase receptor A (TrkA), calcitonin gene-related peptide (CGRP), and substance P (SP) (Averill et al., 1995; Fundin et al., 1997; Mendell et al., 1999). Glial cell line-derived neurotrophic factor (GDNF)-dependent nociceptors typically lack neuropeptides (e.g., CGRP and SP) and bind isolectin B4 (IB4) (Molliver et al., 1997; Bennett et al., 1998). In a recent analysis of GDNFoverexpressing mice (Zwick et al., 2002), we found an increased number of IB4-positive neurons. Because these neurons are heat sensitive (Stucky and Lewin, 1999; Dirajlal et al., 2003), an increase in the number of TRPV1-positive neurons was also expected in these animals. However, no increase in the number of TRPV1 neurons was observed, and analysis of wild-type mice found that only $6 \%$ of mouse DRG neurons were positive for both IB4 and TRPV1 (Zwick et al., 2002). This was in sharp contrast to studies in rat that found that $>50 \%$ of IB4-positive neurons also express TRPV1 (Guo et al., 1999).

These observations raised interesting questions concerning the importance of TRPV1 for detection of noxious heat and the extent to which results from one rodent species could be generalized to a different species regarding the neurochemistry of nociceptors. To more thoroughly analyze these issues, we obtained antibodies that were specific for the mouse and rat forms of TRPV1 to insure that the previous results from our laboratory were not attributable to antibody specificity issues. In addition, 
intracellular physiology recordings were made from primary afferents in TRPV $1^{-1-}$ mice to determine whether deficits in heat responsiveness could be detected.

\section{Materials and Methods}

Animals. Male and female Sprague Dawley rats, Long-Evans rats, BALB/c mice, and $\mathrm{C} 3 \mathrm{H} / \mathrm{Bl} 6$ mice 2-4 months of age were purchased from Harlan (Indianapolis, IN). Mice were anesthetized deeply with $2.5 \%$ avertin (2,2,2-tribromoethanol and tert-amyl alcohol diluted in $0.9 \%$ saline) and perfused transcardially with $4 \%$ paraformaldehyde in $0.1 \mathrm{~m}$ phosphate buffer $(\mathrm{PB})$. Both strains of rat were anesthetized with sodium pentobarbital (40 mg/kg, i.p.) and perfused transcardially with $0.9 \%$ saline solution, followed by $4 \%$ paraformaldehyde in $0.1 \mathrm{M}$ PB. These studies were performed in accordance with the guidelines of the University of Pittsburgh Institutional Animal Care and Use Committee and the National Institutes of Health Guide for the Care and Use of Laboratory Animals.

Immunolabeling and histochemical procedures for IB4/TRPV1 colabeling. Dorsal root ganglia (DRGs) (L4/L5) were removed, immersed in $4 \%$ paraformaldehyde for $1 \mathrm{hr}$, embedded in $10 \%$ gelatin in $0.1 \mathrm{M} \mathrm{PB}$ that was also fixed in $4 \%$ paraformaldehyde until firm, and then placed in $25 \%$ sucrose in $0.1 \mathrm{M} \mathrm{PB}$ overnight at $4^{\circ} \mathrm{C}$. Sections were cut at $25 \mu \mathrm{m}$ on a sliding microtome, blocked $1 \mathrm{hr}$ at room temperature in 5\% NGS and $0.25 \%$ Triton X-100, and incubated overnight in primary antibody at room temperature. Antibodies recognizing the following antigens were used: a rabbit antibody against the $\mathrm{N}$ terminus of the rat sequence of TRPV1 (RASLDSEESESPPQENSC), designated TRPV1R (diluted 1:2000; Neuromics, Minneapolis, MN), and a guinea pig antibody against the $\mathrm{C}$ terminus of the mouse sequence of TRPV1 (EDAEVFKDSMAPGEK), designated TRPV1M (diluted 1:600; provided by Dr. David Julius, University of California at San Francisco, San Francisco, CA). The lectin IB4 conjugated to the fluorophore FITC (diluted 1:100; Sigma, St. Louis, MO) was also used. After overnight incubation, primary antibody binding was visualized using fluorescent secondary antibodies (antirabbit IgG conjugated to Cy2 (1:200) or Cy5 (1:100) and anti-guinea pig IgG conjugated to Cy3 (1:200; Jackson ImmunoResearch, West Grove, $\mathrm{PA})$. Tissue was washed twice in $0.1 \mathrm{M} \mathrm{PB}$, incubated in secondary antibody for $2 \mathrm{hr}$ at room temperature, washed twice in $0.1 \mathrm{M} \mathrm{PB}$, and mounted on slides using DPX (Electron Microscopy Sciences, Ft. Washington, PA). Images were acquired using a $20 \times$ objective on a Leica confocal microscope. Under the sequential scanning mode, sections were scanned and images from three sections from each ganglion were acquired. The number of positively labeled cells for each marker and cells that had overlapping labeling were counted. The percentage of labeled cells and cells with overlapping labeling were compared using an unpaired $t$ test with significance set at $p \leq 0.05$. All statistical tests were performed after fulfillment of all necessary prerequisites using the StatView software package (Abacus Concepts, Berkeley, CA).

Ex vivo physiology preparation. The ex vivo cutaneous somatosensory system preparation has been described in detail previously (Woodbury et al., 2001). Briefly, adult mice were anesthetized via intramuscular injection of ketamine and xylazine (90 and $10 \mathrm{mg} / \mathrm{kg}$, respectively) and perfused transcardially with oxygenated $\left(95 \% \mathrm{O}_{2}-5 \% \mathrm{CO}_{2}\right)$ artificial CSF (aCSF; in mm: $1.9 \mathrm{KCl}, 1.2 \mathrm{KH}_{2} \mathrm{PO}_{4}, 1.3 \mathrm{MgSO}_{4}, 2.4 \mathrm{CaCl}_{2}, 26.0$ $\mathrm{NaHCO}_{3}$, and 10.0 D-glucose) with $253.9 \mathrm{~mm}$ sucrose at $12-15^{\circ} \mathrm{C}$. The spinal cord, thoracic and upper lumbar DRGs, dorsal cutaneous nerves (DCNs), and dorsolateral trunk skin on one side were dissected and transferred to a separate recording chamber containing chilled oxygenated aCSF in which the sucrose was replaced with $127.0 \mathrm{~mm} \mathrm{NaCl}$. The preparation was pinned out with the epidermal surface of the skin facing upward and placed in a recording bath at $30-31^{\circ} \mathrm{C}$ for electrophysiological recording.

Sensory neuron somata were impaled with glass microelectrodes (>100 M $\Omega$ ) containing 5-20\% Neurobiotin (Vector Laboratories, Burlingame, CA) in $1 \mathrm{~m}$ potassium acetate. Electrical search stimuli were delivered through a suction electrode on the nerve to locate afferents with a peripheral process in the DCNs. Peripheral receptive fields were located with a blunt glass stylus.

Evoked activity was digitized on tape for subsequent off-line analyses.
After physiological characterization, the cell was labeled by injecting Neurobiotin iontophoretically (one cell per DRG). Peripheral conduction velocity was calculated from spike latency and the distance between stimulating and recording electrodes (measured directly along the nerve). Heating responses were determined using a computer-controlled peltier device that delivered a $31-52^{\circ} \mathrm{C}$ heat ramp. The temperature $52^{\circ} \mathrm{C}$ was chosen as the maximal temperature because single units could be heated to this temperature repeatedly without apparent loss of function. Higher temperatures appeared to damage afferents, as evidenced by their inability to respond to a second heat ramp.

Tissue processing and analysis of recorded cells. Once a sensory neuron was characterized and filled with Neurobiotin, the DRG containing the injected cell was removed and immersion fixed (4\% paraformaldehyde in $0.1 \mathrm{M} \mathrm{PB}$ for $30 \mathrm{~min}$ at $4^{\circ} \mathrm{C}$ ). Ganglia were then blocked, embedded in $10 \%$ gelatin, postfixed, and cryoprotected in $20 \%$ sucrose overnight. Frozen sections $(40-50 \mu \mathrm{m})$ were serially collected in PB and reacted with fluorescently-tagged avidin to label Neurobiotin-filled cells (Vector Laboratories). Next, each section was stained for either IB4 binding (Molecular Probes, Eugene, OR) or CGRP immunohistochemistry (Chemicon, Temecula, CA), TRPV1 immunohistochemistry (primary antibody generously provided by Dr. D. Julius), or TRPV2 immunohistochemistry (primary antibody provided by M.J.C.). In some cases, IB4 staining was combined with immunohistochemistry for CGRP, TRPV1, or TRPV2. All primary antibodies were prepared in rabbit. After incubation in primary antiserum, tissue was washed and incubated in goat anti-rabbit secondary antiserum (conjugated to Cy2, Cy3, or Cy5 and diluted 1:200; Molecular Probes). Distribution of fluorescent staining was determined using an Olympus confocal microscope and sequential scanning to prevent bleed-through of the different fluorophores.

\section{Results \\ TRPV1 is present in a minority of mouse IB4-positive afferents}

One explanation for the previous difference observed in rat and mouse with respect to the overlap of TRPV1 and IB4 staining is that the TRPV1 antibody used for analyzing mouse ganglia was directed against the $\mathrm{N}$ terminus of the rat TRPV1 sequence, which only overlaps $78 \%$ with the $\mathrm{N}$ terminus of mouse TRPV1. We therefore repeated this analysis using TRPV1 antibodies generated against a rat TRPV1 sequence (TRPV1R) and one generated against a mouse sequence of TRPV1 (TRPV1M).

The TRPV1M antiserum was made to the $C$ terminus of mouse TRPV1, which differs from rat TRPV1 by a single amino acid (Ala in mouse vs Val in rat). Thus, both the C-terminus TRPV1M and the N-terminus TRPV1R were expected to produce similar staining patterns in rat DRG. Double immunolabeling of Sprague Dawley or Long-Evans rat L4/L5 ganglia showed that $98-99 \%$ of TRPV1R-positive neurons were also positive for TRPV1M (data not shown). Using the rat-specific antiserum, we found that $57 \pm 3.2 \%$ of Sprague Dawley IB4-positive neurons and $48 \pm 2.5 \%$ of Long-Evans IB4-positive neurons stained for TRPV1R (Fig. 1 $a-f$ ), confirming the results of previous studies (Guo et al., 1999; Michael and Priestley, 1999).

In mouse, coexpression patterns were quite different from those observed in rat. Previously, using the rat-specific TRPV1R antiserum, we found only $2 \%$ of IB4-positive L4/L5 neurons were TRPV1 positive (Zwick et al., 2002). Using the more specific TRPV1M antibody, a slight increase in the percentage of TRPV1/ IB4-positive neurons was detected. In the $\mathrm{C} 3 \mathrm{H} / \mathrm{Bl} 6$ mouse strain, $5.4 \pm 1.4 \%$ of IB4-positive neurons were TRPV1M positive (Fig. $1 g-i)$. Similarly, the DRG population in BALB/c mice expressed a low percentage $(1.8 \pm 0.3 \%)$ (Fig. $1 j-l)$ of TRPV1M/IB4-positive neurons. 
TRPV1 ${ }^{-/-}$IB4-positive nociceptors have normal heat responses

To determine whether mouse IB4-positive sensory neurons require TRPV1 to exhibit normal heat responses, an ex vivo physiological preparation was used in which skin, DRG, and spinal cord from wild-type $(\mathrm{C} 57 \mathrm{BL} / 6)$ and TRPV1 ${ }^{-1-}$ mice (Caterina et al., 2000) were maintained in oxygenated aCSF. This preparation produces stable recordings from sensory neurons for up to 24 hr (Koerber and Woodbury, 2002; Woodbury and Koerber, 2003) while allowing mechanical and thermal stimulation of the skin and filling of neuronal somata with Neurobiotin for later neurochemical characterization (Fig. 2). Intracellular recordings were made from 33 wild-type (from 9 mice) and

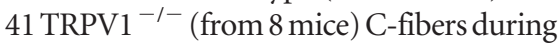
a $21^{\circ} \mathrm{C}$ heat ramp (from 31 to $52^{\circ} \mathrm{C}$ ). Nineteen of the 33 wild-type and 32 of 41 TRPV $1^{-1-}$ fibers exhibited a heat response (Fig. $3 a-d$ ) indicating that there was a small, but significant, increase in the percentage of heat-responsive C-fibers in $\mathrm{TRPV}^{-1-}$ mice [57\% (wild type) vs 78\% $\left(\mathrm{TRPV}^{-1-}{ }^{-1}\right.$ ) Fisher's exact probability test; $p=0.05]$. The mean threshold for firing of wild-type and TRPV1 ${ }^{-/-}$neurons was not significantly different from wild-type mice for either the first or second spike in the heat response (first action potential: wild type, $43.1 \pm$ $0.99^{\circ} \mathrm{C}$; $\mathrm{TRPV} 1^{-1-}, 44.0 \pm 0.85^{\circ} \mathrm{C}$; second action potential: wild type, $44.7 \pm 0.85^{\circ} \mathrm{C}$; $\left.\mathrm{TRPV}^{-/-}, 45.8 \pm 0.84^{\circ} \mathrm{C}\right)$. In addition, wild-type and TRPV1 ${ }^{-1-}$ neurons exhibit virtually identical frequency coding during the heat ramp (Fig. 4). These results are significantly different from previous recordings in TRPV $1^{-1-}$ mice using a skin nerve preparation that found that one-third of the normal number of cutaneous C-fibers responded to noxious heat, and those that responded had, on average, a $45 \%$ decrease in discharge rate (Caterina et al., 2000). Both the skin nerve and ex vivo preparation randomly sample primary afferents, and thus sample bias does not explain the difference in results. One potential contributing factor is that the skin nerve preparation involves recording from the saphenous nerve that innervates hairy skin of the hindlimb, whereas the ex vivo preparation was performed on backskin and its innervating DCNs.

Physiologically characterized C-fibers identified based on Neurobiotin labeling were stained for CGRP, TRPV1, TRPV2, or IB4. In wild-type mice, 7 of 10 heat-responsive C-mechanoreceptors were IB4 positive, whereas in TRPV $1^{-/-}$mice, 11 of 14 cells were IB4 positive. That C-fibers innervating the skin are predominately IB4 positive has been reported previously by Lu et al. (2001), who showed 70\% of epidermal fibers were IB4 positive and TrkA negative. Although we did not exhaustively test the neurochemical phenotype of the IB4-negative population in wild-type and TRPV1 ${ }^{-1-}$ mice, it is highly likely that they would
IB4

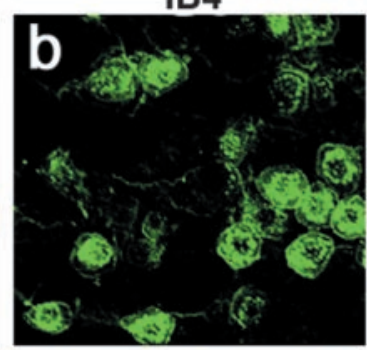

\section{TRPV1R/B4}
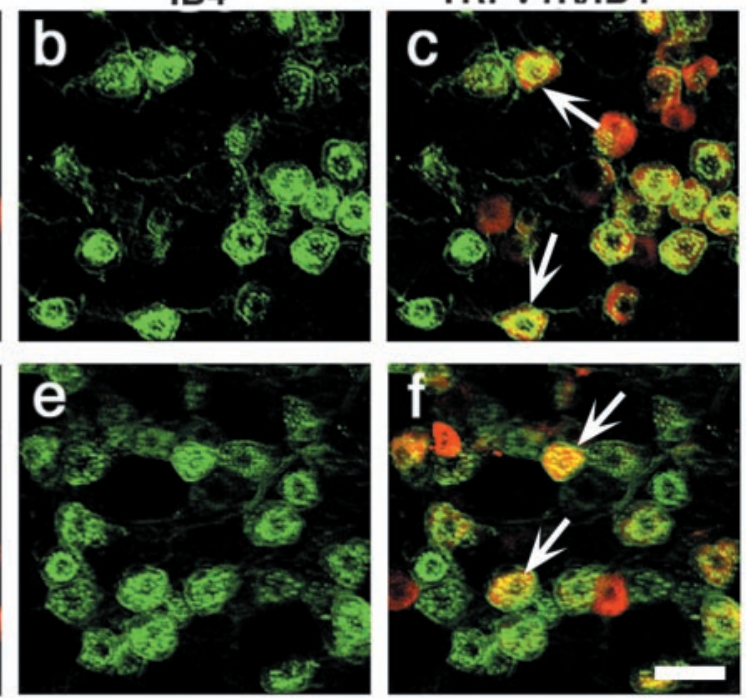

IB4

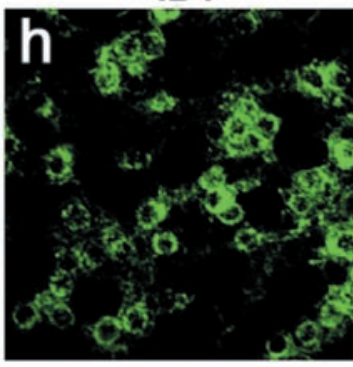

TRPV1M/IB4
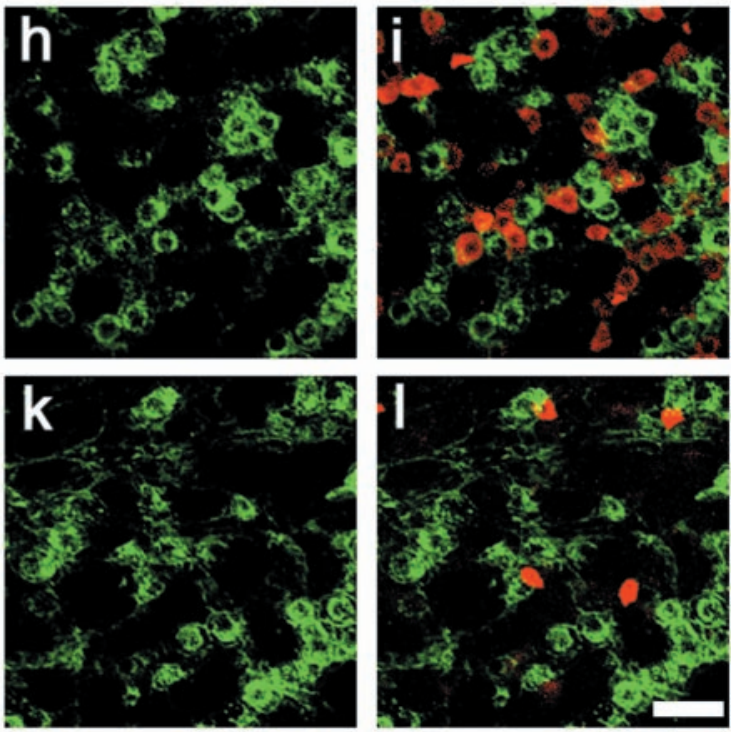

Figure 1. Confocal images showing colocalization of TRPV1 immunoreactivity with IB4 histochemistry in two strains of rat and mouse. Two TRPV1 antibodies, one specific for the rat sequence of TRPV1 (TRPV1R) and one specific for the mouse sequence of TRPV1R ( $a, d$, red) and IB4 ( $b, e$, green) in Sprague Dawley and Long-Evans rats show extensive overlap ( $c, f$, arrows). Unlike rat, double labeling in mouse with TRPV1M $(g, j)$ and IB4 $(h, k)$ revealed minimal overlap $(i, l)$ in both BALB/c and C3H/BL6 mice. The appearance of fewer TRPV1-positive neurons in BALB/c ganglia ( $j$ ) correlates with studies of Mogil et al. (1999) that show BALB/c mice are less sensitive to noxious stimuli relative to other mouse strains. Scale bars, $50 \mu \mathrm{m}$.

have been peptidergic based on the consensus that the majority of nociceptors are either NGF [and express CGRP (Averill et al., 1995)] or GDNF [and express IB4 (Molliver et al., 1997)] dependent (Snider and McMahon, 1998). Moreover, there was no difference in the heat threshold of the IB4-negative cells compared with IB4-positive cells in wild-type or TRPV1 ${ }^{-1-}$ mice (wildtype mice: first action potential, $45.3 \pm 2.04^{\circ} \mathrm{C}$; second action potential, $46.3 \pm 2.04 ; n=3$; TRPV $1^{-1-}$ mice: first action potential, $42 \pm 3.5^{\circ} \mathrm{C}$; second action potential, $\left.43.6 \pm 6.5^{\circ} \mathrm{C} ; n=3\right)$. These results suggest both IB4-negative (i.e., putative peptidergic neurons) and IB4-positive heat-responsive polymodal nociceptors were unaffected in their heat responses by the absence of TRPV1.

In TRPV $1^{-1-}$ mice, 12 of the heat-responsive C-fibers were 


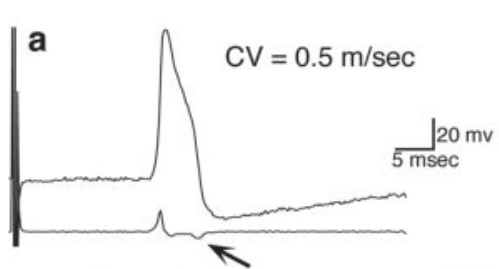

d

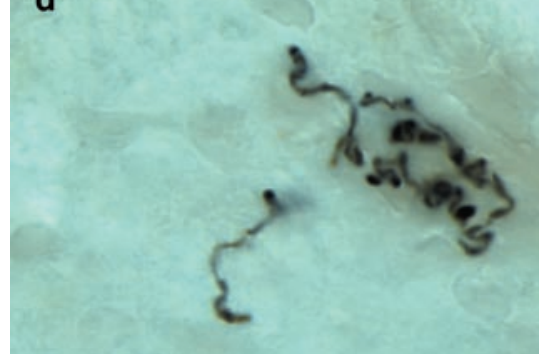

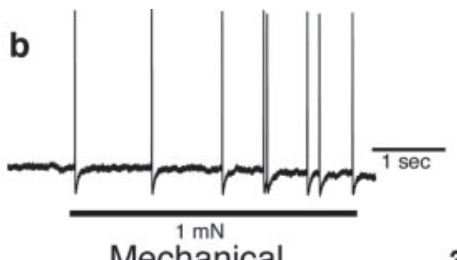

Mechanical

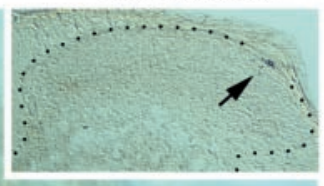

c
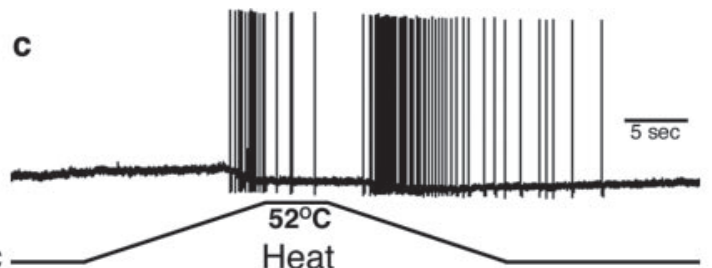
Heat

$31^{\circ} \mathrm{C}$
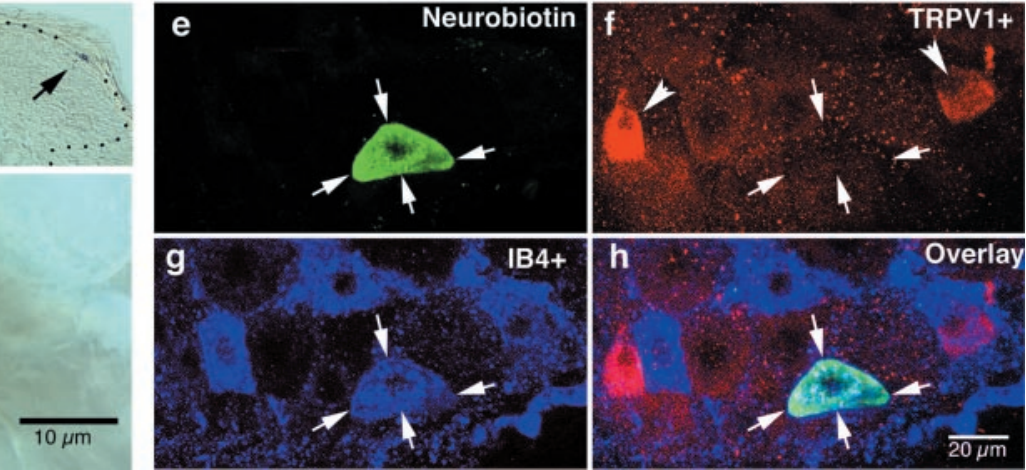

Figure 2. Comprehensive phenotype of a single IB4-positive, TRPV1-negative polymodal nociceptor in a wild-type mouse. A wild-type C-fiber was characterized physiologically, injected with Neurobiotin, and stained for IB4 and TRPV1. $a$, Top trace, Intracellularly recorded action potential exhibiting inflection on the falling phase characteristic of C-fibers. Bottom trace, First derivative of top trace showing change in the slope (arrow) of the falling phase of the somal action potential. CV, Conduction velocity. $b$, $c$, Mechanical and heat responses, respectively, of the same neuron shown in $a$. $d$, Dorsal horn projection of the afferent shown in $a-c$, visualized by DAB staining for Neurobiotin. Inset, Dotted line indicates margin of dorsal horn gray matter and shows that this fiber terminates in lamina I. e, Confocal imaging of Neurobiotin-lableled soma of the afferent shown in $a-d$ (arrows) colabeled for TRPV1 ( $f$ ) and IB4 ( $g$ ). $f$, TRPV1 staining shows the Neurobiotin-filled soma was TRPV1 negative (TRPV1-positive somata are indicated by arrowheads). $g$, IB4 staining of the same section shows that the Neurobiotin-filled cell is IB4 positive. $h$, 0 verlay of $e-g$ confirms that this afferent is IB4 positive and TRPV1 negative.

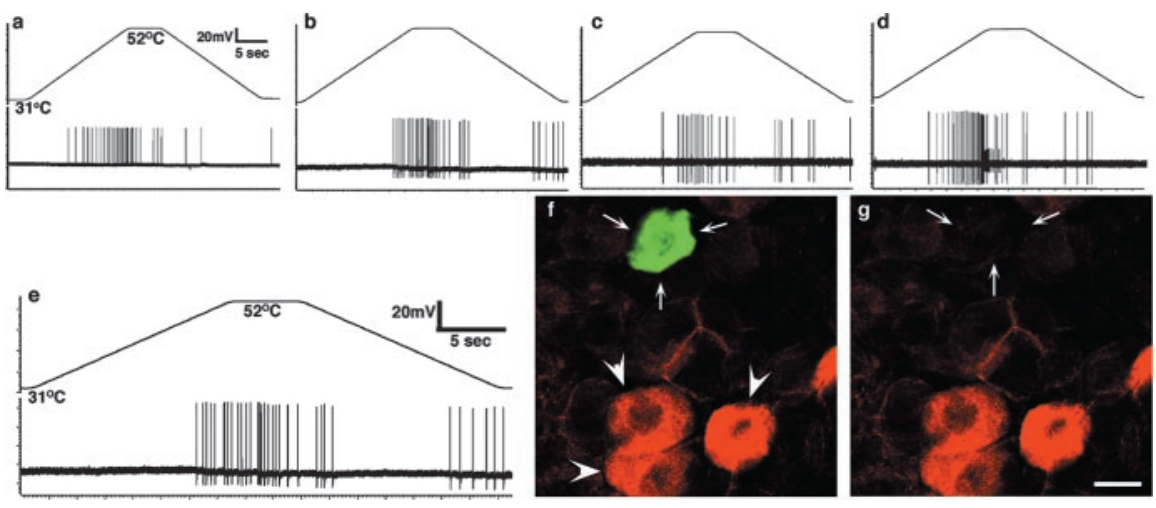

Figure 3. Normal heat responses occur in the absence of TRPV1 and TRPV2. $a, b$, Examples of intracellularly recorded responses to a $21^{\circ} \mathrm{C}$ heat ramp from wild-type, IB4-positive C-fibers. $c$, $d$, Heat responses from IB4-positive C-fibers from two different TRPV1 ${ }^{-1-}$ mice. $e$, Heat response from a C-fiber in a TRPV ${ }^{-1-}$ mouse that was subsequently filled with Neurobiotin and labeled for TRPV2 $(f, g) . f$, Double-label confocal image showing Neurobiotin-stained cell that exhibited heat response seen in $e$ (arrows) and TRPV2-positive cells (arrowheads). $g$, Neurobiotin-filled cell is TRPV2 negative. Only 1 of 12 heat-responsive cells in TRPV1 ${ }^{-1-}$ mice was TRPV2 positive. Scale bar, $20 \mu \mathrm{m}$.

incubated with anti-TRPV2 antiserum (Fig. $3 e-g$ ). Only one of these neurons was immunopositive for this putative heat channel, indicating that heat responses indistinguishable from those seen in wild-type mice could be recorded in the absence of TRPV1 or TRPV2.

\section{Discussion}

These studies were prompted by our inability to reconcile the lack of TRPV1 staining in IB4-positive mouse afferents (Zwick et al., 2002) with the extensive evidence that these neurons are a major population of cutaneous heat-responsive nociceptors (Averill et al., 1995; Molliver et al., 1995; Stucky and Lewin, 1999; Lu et al., 2001; Dirajlal et al., 2003). The results support the concept that normal heat responses are present in IB4-positive neurons in the absence of TRPV1 or TRPV2. We cannot rule out that the normal heat response seen in the TRPV $1^{-1-}$ mice was attributable to TRPV3. This seems unlikely, however, because TRPV3 appears to have a lower threshold for heat activation than TRPV1 (Smith et al., 2002; Benham et al., 2003). The threshold for TRPV3 is controversial, but even the highest observed value is $4-5^{\circ} \mathrm{C}$ below the threshold of the recordings seen in wild-type or TRPV $1^{-1-}$ mice. Second, TRPV3 shows dramatic sensitization to repeated heating (Smith et al., 2002), and this was never seen in our recordings from IB4-positive polymodal fibers. Finally, TRPV3 protein is colocalized with TRPV1 (at least in human) and has been proposed to exist as a heteromer (Smith et al., 2002). The lack of TRPV1 in mouse IB4-positive neurons suggests that TRPV3 is also not expressed in these cells.

The most compelling evidence that TRPV1 was the primary heat-responsive channel was that dissociated neurons from TRPV $1^{-1-}$ sensory ganglia exhibited no, or greatly attenuated, heat currents (Caterina et al., 2000; Davis et al., 2000). TRPV2 was considered a likely candidate for sensing temperatures above $52^{\circ} \mathrm{C}$ based on its similarity to TRPV 1 and its ability to detect high heat stimuli in heterologous systems (Caterina et al., 2000; Davis et al., 2000). In either dissociated cell cultures or heterologous systems, sensory neurons (or their cell line equivalents) only approximate the intact neuron lacking normal central and peripheral processes and, in many aspects, are better models of axotomized neurons than of normal afferents. Thus, the most parsimonious explanation of the previous results and those presented here is that in normal intact mice (or at least in complete 


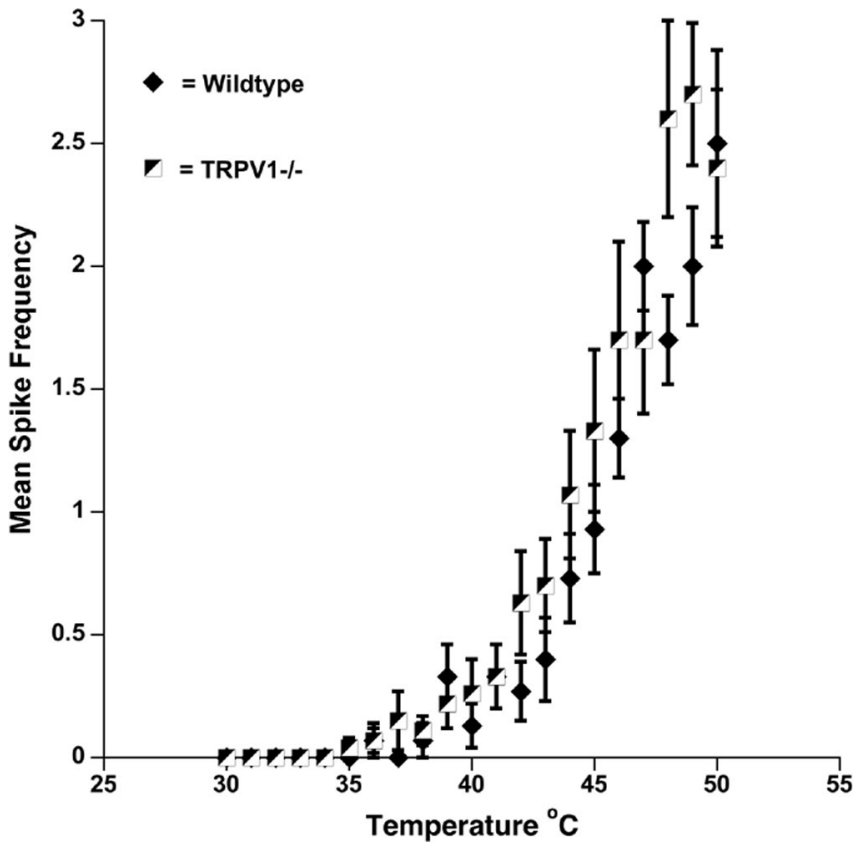

Figure 4. Instantaneous spike frequency for heat-responsive (-fibers in wild-type and $\mathrm{TRPV}^{-1-}$ mice. Neurons from wild-type (blue) and TRPV1 ${ }^{-1-}$ (red) mice exhibited increased firing frequency during the heat ramp in the ex vivo preparation. There was no difference in the response properties of the two mouse lines.

intact afferents, as is the case in the ex vivo preparation), at least two different mechanisms are present for detecting heat, a TRPV1-dependent and a TRPV1/2-independent mechanism. Our working hypothesis is that the TRPV1/2-independent mechanism is fully functional only when all portions of the afferent are present. The TRPV1/2-dependent mechanism becomes important after injury or in disease states and functions in isolated cells as seen in the knock-out studies. Supporting evidence that TRPV1 is not required for heat responses in intact animals is that in studies using TRPV $1^{-/-}$mice, normal behavioral responses to noxious heat are measured, except at high temperatures that exceed those typically used to detect heat thresholds (Caterina et al., 2000; Davis et al., 2000; Moriyama et al., 2003). That TRPV1 is important in pathological states is further suggested by its ability to respond, and be potentiated by, multiple stimuli including those that are physical (heat and mechanical) and chemical (e.g., vanilloid compounds and acid). In addition, TRPV1 currents can be potentiated by interactions with G-coupled proteins like the bradykinin receptors (Shin et al., 2002; Sugiura et al., 2002; Carr et al., 2003; Ferreira et al., 2004) and the P2Y2 ATP receptor (Moriyama et al., 2003). It is also important to note that behavioral heat hyperalgesia induced by either complete Freund's adjuvant, carrageenan, or ATP is absent in TRPV1 ${ }^{-/-}$mice (although pretreatment responses are normal) (Caterina et al., 2000; Davis et al., 2000; Moriyama et al., 2003). Finally, recent studies indicate that TRPV1 protein is increased in a p38 mitogen-activated protein kinase-dependent manner after inflammation (Ji et al., 2002). Thus, there is little doubt that TRPV1 is important for understanding the biology of pain. However, the present study shows that a major population of nociceptors (those that express IB4) use another mechanism under normal conditions to detect noxious heat and that this mechanism does not require the presence of functional TRPV1 or TRPV2.

\section{References}

Averill S, McMahon SB, Clary DO, Reichardt LF, Priestley JV (1995) Immunocytochemical localization of trkA receptors in chemically identified subgroups of adult rat sensory neurons. Eur J Neurosci 7:1484-1494.

Benham CD, Gunthorpe MJ, Davis JB (2003) TRPV channels as temperature sensors. Cell Calcium 33:479-487.

Bennett DL, Michael GJ, Ramachandran N, Munson JB, Averill S, Yan Q, McMahon SB, Priestley JV (1998) A distinct subgroup of small DRG cells express GDNF receptor components and GDNF is protective for these neurons after nerve injury. J Neurosci 18:3059-3072.

Carr MJ, Kollarik M, Meeker SN, Undem BJ (2003) A role for TRPV1 in bradykinin-induced excitation of vagal airway afferent nerve terminals. J Pharmacol Exp Ther 304:1275-1279.

Caterina MJ, Schumacher MA, Tominaga M, Rosen TA, Levine JD, Julius D (1997) The capsaicin receptor: a heat-activated ion channel in the pain pathway. Nature 389:816-824.

Caterina MJ, Rosen TA, Tominaga M, Brake AJ, Julius D (1999) A capsaicin-receptor homologue with a high threshold for noxious heat. Nature 398:436-441.

Caterina MJ, Leffler A, Malmberg AB, Martin WJ, Trafton J, Petersen-Zeitz KR, Koltzenburg M, Basbaum AI, Julius D (2000) Impaired nociception and pain sensation in mice lacking the capsaicin receptor. Science 288:306-313

Davis JB, Gray J, Gunthorpe MJ, Hatcher JP, Davey PT, Overend P, Harries MH, Latcham J, Clapham C, Atkinson K, Hughes SA, Rance K, Grau E, Harper AJ, Pugh PL, Rogers DC, Bingham S, Randall A, Sheardown SA (2000) Vanilloid receptor-1 is essential for inflammatory thermal hyperalgesia. Nature 405:183-187.

Dirajlal S, Pauers LE, Stucky CL (2003) Differential response properties of $\mathrm{IB}(4)$-positive and -negative unmyelinated sensory neurons to protons and capsaicin. J Neurophysiol 89:513-524.

Ferreira J, da Silva GL, Calixto JB (2004) Contribution of vanilloid receptors to the overt nociception induced by $\mathrm{B} 2$ kinin receptor activation in mice. Br J Pharmacol 141:787-794

Fundin BT, Silos-Santiago I, Ernfors P, Fagan AM, Aldskogius H, DeChiara TM, Phillips HS, Barbacid M, Yancopoulos GD, Rice FL (1997) Differential dependency of cutaneous mechanoreceptors on neurotrophins, trk receptors, and P75 LNGFR. Dev Biol 190:94-116.

Guler AD, Lee H, Iida T, Shimizu I, Tominaga M, Caterina M (2002) Heatevoked activation of the ion channel, TRPV4. J Neurosci 22:6408-6414.

Guo A, Vulchanova L, Wang J, Li X, Elde R (1999) Immunocytochemical localization of the vanilloid receptor 1 (VR1): relationship to neuropeptides, the P2X3 purinoceptor and IB4 binding sites. Eur J Neurosci 11:946-958.

Ji RR, Samad TA, Jin SX, Schmoll R, Woolf CJ (2002) p38 MAPK activation by NGF in primary sensory neurons after inflammation increases TRPV1 levels and maintains heat hyperalgesia. Neuron 36:57-68.

Koerber HR, Woodbury CJ (2002) Comprehensive phenotyping of sensory neurons using an ex vivo somatosensory system. Physiol Behav 77:589-594.

Lu J, Zhou XF, Rush RA (2001) Small primary sensory neurons innervating epidermis and viscera display differential phenotype in the adult rat. Neurosci Res 41:355-363.

Ma QP (2001) Vanilloid receptor homologue, VRL1, is expressed by both A- and C-fiber sensory neurons. NeuroReport 12:3693-3695.

Mendell LM, Albers KM, Davis BM (1999) Neurotrophins, nociceptors, and pain. Microsc Res Tech 45:252-261.

Michael GJ, Priestley JV (1999) Differential expression of the mRNA for the vanilloid receptor subtype 1 in cells of the adult rat dorsal root and nodose ganglia and its downregulation by axotomy. J Neurosci 19:1844-1854.

Mogil JS, Wilson SG, Bon K, Lee SE, Chung K, Raber P, Pieper JO, Hain HS, Belknap JK, Hubert L, Elmer GI, Chung JM, Devor M (1999) Heritability of nociception II. "Types" of nociception revealed by genetic correlation analysis. Pain 80:83-93.

Molliver DC, Radeke MJ, Feinstein SC, Snider WD (1995) Presence or absence of TrkA protein distinguishes subsets of small sensory neurons with unique cytochemical characteristics and dorsal horn projections. J Comp Neurol 361:404-416.

Molliver DC, Wright DE, Leitner ML, Parsadanian AS, Doster K, Wen D, Yan Q, Snider WD (1997) IB4-binding DRG neurons switch from NGF to GDNF dependence in early postnatal life. Neuron 19:849-861.

Moriyama T, Iida T, Kobayashi K, Higashi T, Fukuoka T, Tsumura H, Leon C, 
Suzuki N, Inoue K, Gachet C, Noguchi K, Tominaga M (2003) Possible involvement of P2Y2 metabotropic receptors in ATP-induced transient receptor potential vanilloid receptor 1-mediated thermal hypersensitivity. J Neurosci 23:6058-6062.

Peier AM, Reeve AJ, Andersson DA, Moqrich A, Earley TJ, Hergarden AC, Story GM, Colley S, Hogenesch JB, McIntyre P, Bevan S, Patapoutian A (2002) A heat-sensitive TRP channel expressed in keratinocytes. Science 296:2046-2049.

Shin J, Cho H, Hwang SW, Jung J, Shin CY, Lee SY, Kim SH, Lee MG, Choi YH, Kim J, Haber NA, Reichling DB, Khasar S, Levine JD, Oh U (2002) Bradykinin-12-lipoxygenase-VR1 signaling pathway for inflammatory hyperalgesia. Proc Natl Acad Sci USA 99:10150-10155.

Smith GD, Gunthorpe MJ, Kelsell RE, Hayes PD, Reilly P, Facer P, Wright JE, Jerman JC, Walhin JP, Ooi L, Egerton J, Charles KJ, Smart D, Randall AD, Anand P, Davis JB (2002) TRPV3 is a temperature-sensitive vanilloid receptor-like protein. Nature 418:186-190.

Snider WD, McMahon SB (1998) Tackling pain at the source: new ideas about nociceptors. Neuron 20:629-632.

Stucky CL, Lewin GR (1999) Isolectin B(4)-positive and -negative nociceptors are functionally distinct. J Neurosci 19:6497-6505.

Sugiura T, Tominaga M, Katsuya H, Mizumura K (2002) Bradykinin lowers the threshold temperature for heat activation of vanilloid receptor 1 . J Neurophysiol 88:544-548.

Watanabe H, Vriens J, Suh SH, Benham CD, Droogmans G, Nilius B (2002) Heat-evoked activation of TRPV4 channels in a HEK293 cell expression system and in native mouse aorta endothelial cells. J Biol Chem 277:47044-47051.

Woodbury CJ, Koerber HR (2003) Widespread projections from myelinated nociceptors throughout the substantia gelatinosa provide novel insights into neonatal hypersensitivity. J Neurosci 23:601-610.

Woodbury CJ, Ritter AM, Koerber HR (2001) Central anatomy of individual rapidly adapting low-threshold mechanoreceptors innervating the "hairy" skin of newborn mice: early maturation of hair follicle afferents. J Comp Neurol 436:304-323.

Xu H, Ramsey IS, Kotecha SA, Moran MM, Chong JA, Lawson D, Ge P, Lilly J, Silos-Santiago I, Xie Y, DiStefano PS, Curtis R, Clapham DE (2002) TRPV3 is a calcium-permeable temperature-sensitive cation channel. Nature 418:181-186.

Zwick M, Davis BM, Woodbury C, Burkett JN, Koerber HR, Simpson JF, Albers KM (2002) Glial cell line-derived neurotrophic factor is a survival factor for isolectin B4-positive, but vanilloid receptor 1-positive, neurons in the mouse. J Neurosci 22:4057-4065. 